\title{
SEMIEMPIRICAL CONFORMATIONAL ANALYSIS OF $(R, R)$ - TARTARIC ACID, ITS DIMETHYL DIESTER, DIAMIDE AND N, N, N', N'-TETRAMETHYL DIAMIDE. $A B$-INITIO CALCULATIONS OF SOME MODEL COMPOUNDS
}

\author{
Marcin Hoffmann ${ }^{1}$, Jacek Rychlewski ${ }^{1,2}$, Urszula Rychlewska ${ }^{1}$ \\ ${ }^{1)}$ Department of Chemistry, A. Mickiewicz University, Grunwaldzka 6, 60-780 \\ Poznan, Poland \\ ${ }^{2)}$ Poznan Supercomputing and Networking Center, Wieniawskiego 17/19, \\ 61-713 Poznan, Poland
}

\begin{abstract}
R, R)-tartaric acid $(A C)$, its dimethyl diester $(M E)$, diainide $(A M)$ and $\mathrm{N}, \mathrm{N}, \mathrm{N}^{\prime}, \mathrm{N}^{\prime}-$ tetramethyl diamide (TMA) as well as their model compounds, namely hydroxyacetic acid, its methyl ester and amide, have been studied in order to find general conformational preferences among (RR)-tartaric acid derivatives. A rotation around all rotable bonds have been scanned systematically using semiempirical methods for $A C, M E, A M$ and $T M A$ and ab-initio calculations for the model compounds have been carried out. In the case of $A C$ and $M E$ we found a tendency towards the extended conformation, which is in good agreement with available experimental data. For $A M$ and $T M A$ the results of semiempirical calculations are contradictory to each other. Conformations similar to those observed in the crystal structure were predicted by MNDO in the case of $A M$ (the T conformer) and by PM3 in the case of TMA (the G" conformer). Energetically preferred conformational isomers are stabilized by intramolecular hydrogen bonds and the electrostatic $\mathrm{CO} / \mathrm{C} * \beta \mathrm{H}$ coplanar bond interactions. In $\mathrm{T}$ and $\mathrm{G}^{\prime \prime}$ rotamers, intramolecular hydrogen bonds leading to the formation of five-membered rings prevail, while in $\mathrm{G}^{+}$conformers, hydrogen bonded six-membered rings dominate.
\end{abstract}

\section{Introduction}

(R.R)-tartaric acid (Fig. 1) is the most important compound in the history of stereochemistry. L. Pasteur working on sodium ammonium $(\mathrm{R}, \mathrm{R})$-tartrate discovered

a)

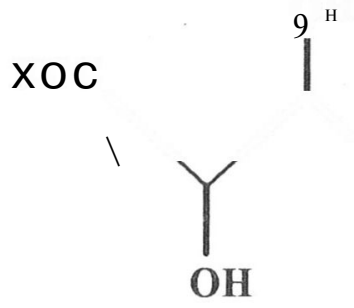

COX b)

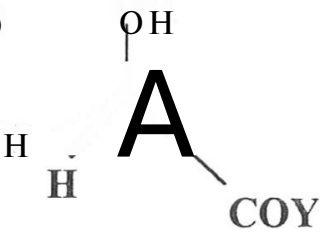

Fig. 1. a) Zig-zag formula of the (R,R)-tartaric acid derivatives, for $A C X=\mathrm{OH}$, for $M E \mathrm{X}=$ $\mathrm{OCH}_{3}, A M \mathrm{X}=\mathrm{NH}_{2}$, TAM X $=\mathrm{N}\left(\mathrm{CH}_{3}\right)_{2} ;$ b) formula of the model compounds, for hydroxyacetic acid $\mathrm{Y}=\mathrm{OH}$, its ester $\mathrm{Y}=\mathrm{OCH}_{3}$, its amide $\mathrm{Y}=\mathrm{NH}_{2}$. 
the phenomenon of the enantiomerism [1], J. M. Bijvoet for the first time assigned an absolute configuration of sodium rubidium tartrate [2], The T conformation (Fig. 2) has been found in $(\mathrm{R}, \mathrm{R})$-tartaric acid [3] by the X-ray analysis. However, N,N, N'. N'tetramethyl tartaric acid diamide was found by the $\mathrm{X}$-ray diffraction analysis to be present in the $\mathrm{G}^{-}$form $[4,5]$,

There were several attempts to predict the conformation of $(\mathrm{R}, \mathrm{R})$-tartaric acid esters on the basis of the vibrational circular dichroism (VCD) results. Early results suggested the $\mathrm{G}^{+}$conformer [6-8], Polvarapu et al performed further VCD measurements and stated that these results can be interpreted in the favor of the $T$ conformation of dimethyl $(\mathrm{R}, \mathrm{R})$ tartrate $(M E)$, but the $\mathrm{G}^{+}$conformer could not be ruled out [9], They carried out ab-initio calculations for seven chosen conformers of<smiles>[R]C1C2CC([R])(C1O)C(O)C2O</smiles>

$\mathrm{T}$ (trans)<smiles>[R]C1C(O)C2CC1C([R])C2O</smiles>

$\mathrm{G}^{+}$(gauche $^{+}$)<smiles>[R]C1C2CC(O)(C1[R])C(O)C2O</smiles>

$\mathrm{G}^{-}$(gauche $)^{-}$

Fig. 2. Notation of rotamers of (R.R)-tartaric acid and its derivatives.

For $A C \mathrm{R}=\mathrm{COOH}, M E \mathrm{R}=\mathrm{COOCH}_{3}, A M \mathrm{R}=\mathrm{CONH}_{2}, T M A \mathrm{R}=\mathrm{CON}\left(\mathrm{CH}_{3}\right)_{2}$.

of $(\mathrm{R}, \mathrm{R})$-tartaric acid up to RHF/6-31G//RHF/STO-3G level [10], They concluded that the $\mathrm{T}$ conformer with the hydrogen bonds between $\alpha-\mathrm{OH}$ and $0=\mathrm{C}$ groups predominates and suggested the same for dimethyl $(R, R)$ tartrate. Results of molecular mechanics and dynamics calculations preferred the $T$ conformation for $(R, R)$-tartaric acid [11], Szarecka et al. performed quantum-chemical calculations concerning (R,R)tartaric acid monoamide monomethyl ester and concluded that for this compound the $\mathrm{T}$ rotamer predominates [12], The $\mathrm{T}$ conformation for (R.R)-tartanc acid and its esters was indicated by ${ }^{13} \mathrm{C}$ NMR data $[13,14]$ and by Raman optical activity (ROA) studies $[15,16]$, On the basis of CD measurements using the benzoate excitation chirality method Gawronski et al. found that $\mathrm{O}, \mathrm{O}^{\prime}$-dibenzoylated $(\mathrm{R}, \mathrm{R})$ tartaric acid, its ethyl mono- and di- esters were in the $\mathrm{T}$ conformation, whereas $\mathrm{O}, \mathrm{O}^{\prime}$-dibenzoilatcd $\mathrm{N}, \mathrm{N}, \mathrm{N}^{\prime}, \mathrm{N}^{\prime}$-tetramethyl diamide of $(\mathrm{R}, \mathrm{R})$-tartaric acid was in the $\mathrm{G}^{-}$form in alcohol solution [4],

These results stimulated our interest in $(\mathrm{R}, \mathrm{R})$-tartaric acid derivatives and prompted us to study the conformations of these compounds systematically using the quantum chemical computational methods. 


\section{Computational Methods}

The standard values of bond lengths, valency and dihedral angles needed to define the proper diastereoisomer were utilized as the initial set of parameters [17],

Model compounds, which had the skeleton of hydroxyacetic acid were studied using ab-initio method. First of all, at $6-31 \mathrm{G}^{* *}$ basis set, we optimized the geometry of a conformer with starting values of both $\mathrm{O}-\mathrm{C}-\mathrm{C}=\mathrm{O}$ and $\mathrm{H}-\mathrm{O}-\mathrm{C}-\mathrm{C}$ torsion angles equal to $180^{\circ}$. The optimized parameters were utilized as the starting geometry for scanning the rotation at $6-31 \mathrm{G}^{*}$ basis set. We scanned the rotation of hydroxyl group and around $\mathrm{C}-\mathrm{C}$ bond at the $30^{\circ}$ grid. These calculations showed, that we may find minima when $\mathrm{O}-\mathrm{C}-\mathrm{C}=\mathrm{O}$ angle is $0^{\circ}$ or $180^{\circ}$

For $(\mathrm{R}, \mathrm{R})$-tartaric acid derivatives semiempirical calculations were carried out. Typical three fold torsion potential with minima around $60^{\circ}, 180^{\circ}, 300^{\circ}$ was assumed for torsion angle $\mathrm{CC}^{*}-\mathrm{C}^{*} \mathrm{C}$ (determining the conformation of the main carbon chain) and both $\mathrm{HO}-\mathrm{C}^{*} \mathrm{C}^{*}$ angles (describing the position of hydroxyl hydrogen atoms). Values close to these dihedrals were found in the case of smaller molecules of similar skeleton [12,18]. We performed preliminary' semiempirical calculations and scanned the rotation about $\mathrm{C}^{*}-\mathrm{C}$ bond at the $10^{\circ}$ grid for all possible (e.i. 27) combinations of rotameric dihedral angles about $\mathrm{C}^{*}-\mathrm{C}^{*}$ and $\mathrm{C}^{*-\mathrm{O}}$ bonds. The results obtained allowed us to state that we may locate a minimum when $\mathrm{O}-\mathrm{C}^{*}-\mathrm{C}=\mathrm{O}$ torsion angle, determining the mutual arrangement of the carbonyl and hydroxyl groups, is about $0^{\circ}, 90^{\circ}, 180^{\circ}$, $270^{\circ}$.

Having preliminary results for $(\mathrm{R}, \mathrm{R})$-tartaric acid derivatives we have examined all possible combinations of rotable dihedral angles during semiempirical calculations at the Neglect of Diatomic Differential Overlap (NDDO) [19] level, with Modified Neglect of Diatomic Differential Overlap (MNDO) [20], the Austin Model 1 (AM1) [21] and Parametrized Model 3 (PM3) [22] hamiltonians. The MNDO, AM1 and PM3 methods were utilized for conformational analysis of $A M$ and TMA. AM1 and PM3 calculations were carried out for $A C$ and $M E$. Since the molecules studied are built of two identical parts we could limit the number of examined conformers and optimize 270 (i.e. $3 * 3 * 3 *(4+3+2+1)$ ) instead of 432 (i.e. $3 * 3 * 3 * 4 * 4$ ) possible conformers.

Ab-initio results for model molecules were obtained with GAUSSIAN94 [23] program on CRAY J916 in Poznan Supercomputing and Networking Center. This package was also used to get semiempirical data for $M E$ and $A C$. MOPAC [24] program package on PC 486 was utilized to collect semiempirical results for $A M$ and $T M A$.

\section{Results and Discussion}

\subsection{Model compounds}

Fig. 3 shows results of scanning the rotation of rotable dihedral angles for hydroxyacetic acid, its methyl ester and amide at $6-31 \mathrm{G}^{*}$ basis set. It is easy to notice 
hydroxyacetic acid

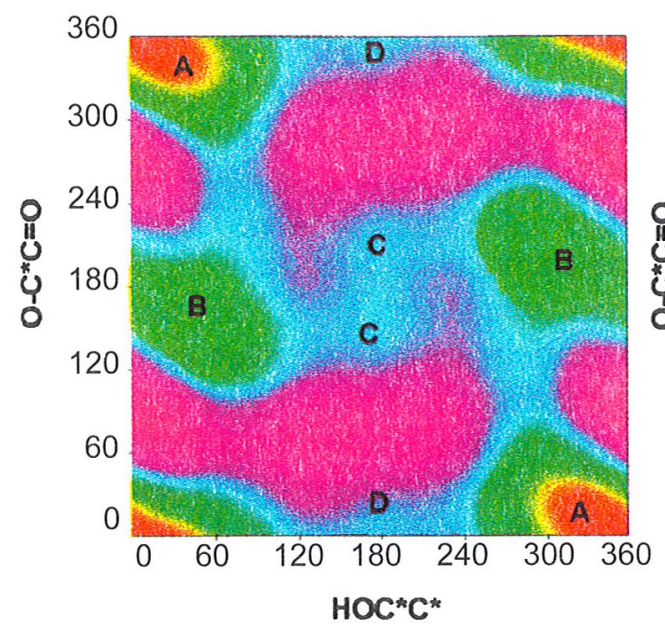

hydroxyacetamide

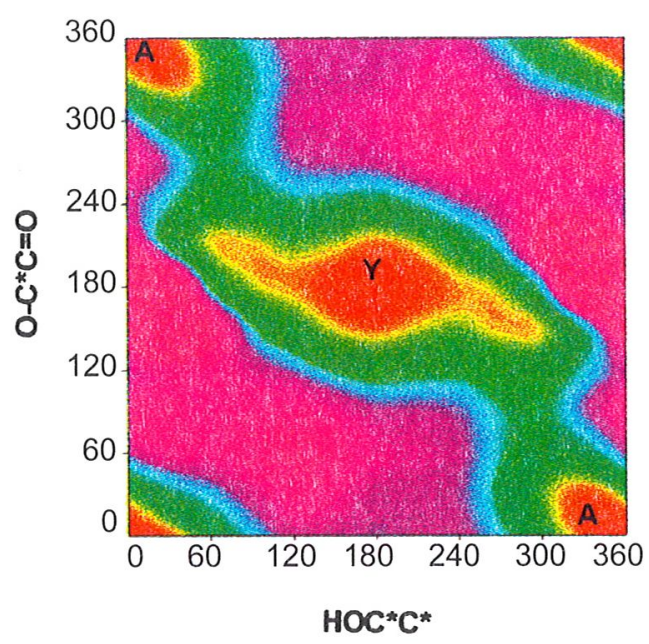

methyl hydroxyacetate

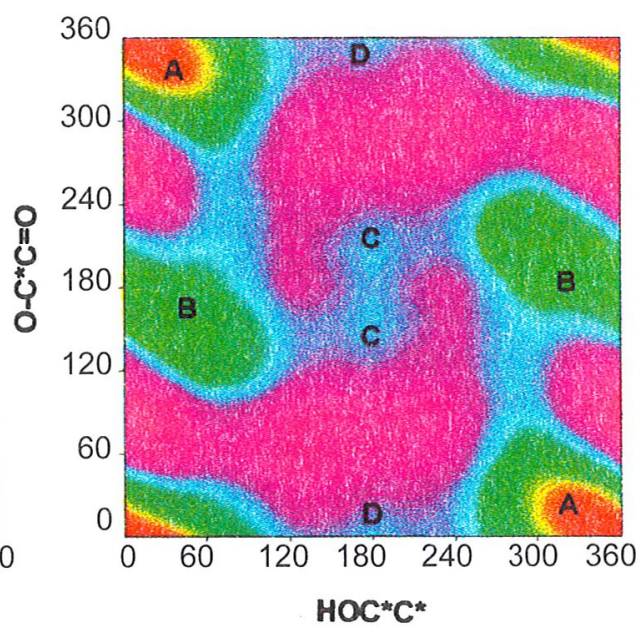

Fig. 3. Relative energy as a function of $\mathrm{HOC}^{*} \mathrm{C}^{*}$ and $\mathrm{O}-\mathrm{C}^{*}=\mathrm{O}$ torsion angles for: hydroxyacetic acid, methyl hydroxyacetate and hydroxyacetamide.

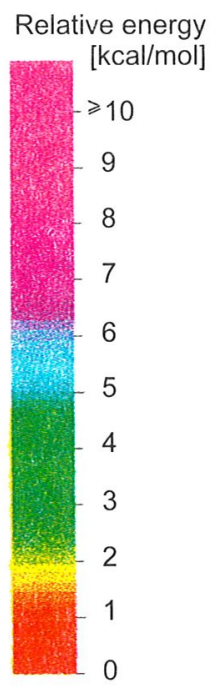


Tab. 1. Selected semiempirieal results for (R,R)-tartaric acid (AC), (fifteen lowest energy conformers listed with some of properties)

\begin{tabular}{|c|c|c|c|c|c|c|c|c|c|c|c|c|c|}
\hline \multicolumn{7}{|c|}{ AM1 } & \multicolumn{7}{|c|}{ PM3 } \\
\hline $\left.\begin{array}{c}\Delta \mathrm{E} \\
{[\mathrm{kcal} / \mathrm{mol}]}\end{array}\right]$ & $\begin{array}{c}\mathrm{D} \\
\text { [debye] }\end{array}$ & $\begin{array}{c}\mathrm{CC}^{*} \mathrm{C}^{*} \mathrm{C} \\
{ }^{\circ} \mathrm{I}\end{array}$ & $\begin{array}{c}\mathrm{O}-\mathrm{C}^{*} \mathrm{C}=\mathrm{O} \\
{\left[{ }^{\circ}\right]}\end{array}$ & $\begin{array}{c}\mathrm{O}-\mathrm{C}^{*} \mathrm{C}=\mathrm{O} \\
{\left[{ }^{\circ}\right]}\end{array}$ & $\begin{array}{c}\mathrm{HOC}^{*} \mathrm{C}^{*} \\
{\left[{ }^{\circ}\right]}\end{array}$ & \begin{tabular}{|c|}
$\mathrm{HOC}^{*} \mathrm{C}^{*}$ \\
{$\left[{ }^{\circ}\right]$}
\end{tabular} & $\begin{array}{c}\Delta \mathrm{E} \\
{[\mathrm{kcal} / \mathrm{mol}]}\end{array}$ & $\begin{array}{c}\mathrm{D} \\
\text { [debye] }\end{array}$ & $\begin{array}{c}\mathrm{CC}^{*} \mathrm{C}^{*} \mathrm{C} \\
{ }^{\circ} \mathrm{C}\end{array}$ & $\begin{array}{c}\mathrm{O}-\mathrm{C}^{*} \mathrm{C}=\mathrm{O} \\
\left.{ }^{\circ}\right]\end{array}$ & $\begin{array}{c}\mathrm{O}-\mathrm{C}^{*} \mathrm{C}=\mathrm{O} \\
{\left[{ }^{\circ}\right]}\end{array}$ & $\begin{array}{c}\mathrm{HOC}^{*} \mathrm{C}^{*} \\
{\left[{ }^{\circ}\right]}\end{array}$ & $\begin{array}{c}\mathrm{HOC}^{*} \mathrm{C}^{*} \\
{\left[{ }^{\circ}\right]}\end{array}$ \\
\hline 0.00 & 0.79 & -143.7 & -172.0 & -172.0 & 72.7 & 72.7 & 0.00 & 0.78 & -168.1 & 22.2 & 22.2 & 75.8 & 75.8 \\
\hline 0.06 & 0.26 & -147.3 & -170.0 & 10.1 & 70.3 & 78.5 & 0.35 & 0.52 & -85.7 & 47.3 & 47.3 & 57.1 & 57.1 \\
\hline 0.26 & 0.89 & -151.2 & 11.0 & 11.0 & 76.0 & 76.0 & 0.78 & 0.20 & -165.6 & 22.7 & -154.3 & 78.4 & 67.7 \\
\hline 0.27 & 0.34 & 60.6 & 176.4 & 176.4 & 66.0 & 66.0 & 0.92 & 0.77 & -81.1 & 46.7 & -128.7 & 58.4 & 52.1 \\
\hline 0.42 & 0.67 & -110.1 & -137.8 & -137.8 & 59.4 & 59.4 & 0.97 & 0.07 & 47.5 & 25.4 & 25.3 & 67.7 & 67.7 \\
\hline 0.42 & 0.54 & -112.0 & 42.3 & -140.9 & 61.3 & 59.3 & 1.58 & 0.89 & 54.2 & 28.7 & -153.8 & 64.8 & 61.5 \\
\hline 0.56 & 0.74 & -113.6 & 41.1 & 41.1 & 60.8 & 60.8 & 1.59 & 0.53 & -75.0 & -125.9 & -126.0 & 53.0 & 53.0 \\
\hline 0.59 & 0.05 & 51.6 & 10.4 & 10.4 & 66.2 & 66.2 & 1.74 & 1.12 & -164.4 & -152.6 & -152.6 & 69.4 & 69.4 \\
\hline 0.67 & 0.87 & 57.1 & 9.2 & -173.5 & 65.6 & 64.9 & 1.96 & 0.16 & 61.3 & 3.2 & 33.5 & 66.8 & 50.2 \\
\hline 0.95 & 0.97 & -155.8 & 156.5 & -172.2 & 170.0 & 62.1 & 2.00 & 0.51 & 57.1 & -158.8 & -158.8 & 60.6 & 60.6 \\
\hline 0.96 & 0.24 & -159.1 & -15.7 & -170.3 & 149.7 & 62.1 & 2.08 & 0.25 & -169.3 & -4.1 & -162.7 & 154.5 & 62.8 \\
\hline 1.26 & 1.25 & \begin{tabular}{|l|}
-157.9 \\
\end{tabular} & 157.1 & 9.7 & 169.5 & 63.6 & 2.37 & 0.85 & 63.8 & 5.4 & -155.2 & 63.4 & 48.2 \\
\hline 1.29 & 1.09 & -161.6 & -15.1 & 9.8 & 147.9 & 64.0 & 2.49 & 1.15 & -168.5 & 169.4 & 18.4 & 176.7 & 68.6 \\
\hline 1.42 & 0.90 & 154.3 & -133.6 & -133.6 & 56.3 & 56.3 & 2.50 & 0.10 & 64.6 & 0.3 & 0.3 & 49.2 & 49.2 \\
\hline 3.07 & 1.06 & 66.2 & 160.0 & 51.7 & 174.4 & 66.3 & 2.82 & 1.20 & 175.9 & 90.3 & 42.2 & 38.0 & -50.7 \\
\hline
\end{tabular}

The lowest energy are (in Hartree) -0.453116 for AM1 and -0.433645 for PM3. $\Delta \mathrm{E}$ - relative energy of the conformer. D - dipole momentum. 
Tab. 2. Selected semiempirical results for dimethyl (R, R)-tartrate (ME), (fifteen lowest energy conformers listed).

\begin{tabular}{|c|c|c|c|c|c|c|c|c|c|c|c|c|c|}
\hline \multicolumn{7}{|c|}{ AMl } & \multicolumn{7}{|c|}{ PM3 } \\
\hline $\begin{array}{c}\Delta \mathrm{E} \\
{[\mathrm{kcal} / \mathrm{mol}]}\end{array}$ & $\begin{array}{c}\text { D } \\
\text { [debye] }\end{array}$ & $\begin{array}{c}\mathrm{CC}^{*} \mathrm{C}^{*} \mathrm{C} \\
{[0]}\end{array}$ & $\begin{array}{c}\mathrm{O}-\mathrm{C}^{*} \mathrm{C}=\mathrm{O} \\
{\left[^{\circ}\right]}\end{array}$ & $\begin{array}{c}\mathrm{O}-\mathrm{C}^{*} \mathrm{C}=\mathrm{O} \\
{\left[{ }^{\circ}\right]}\end{array}$ & $\begin{array}{c}\mathrm{HOC}^{*} \mathrm{C}^{*} \\
\left.{ }^{\circ}\right]\end{array}$ & $\begin{array}{c}\mathrm{HOC}^{*} \mathrm{C}^{*} \\
{\left[{ }^{\circ}\right]}\end{array}$ & $\begin{array}{c}\Delta \mathrm{E} \\
{[\mathrm{kcal} / \mathrm{mol}]}\end{array}$ & $\begin{array}{c}\mathrm{D} \\
\text { [debye] }\end{array}$ & $\begin{array}{c}\mathrm{CC}^{*} \mathrm{C}^{*} \mathrm{C} \\
{ }^{\circ}\end{array}$ & $\begin{array}{c}\mathrm{O}-\mathrm{C}^{*} \mathrm{C}=\mathrm{O} \\
{\left[{ }^{\circ}\right]}\end{array}$ & $\begin{array}{c}\mathrm{O}-\mathrm{C}^{*} \mathrm{C}=\mathrm{O} \\
{\left[{ }^{\circ}\right]}\end{array}$ & $\begin{array}{c}\mathrm{HOC}^{*} \mathrm{C}^{*} \\
{\left[{ }^{\circ}\right]}\end{array}$ & $\begin{array}{c}\mathrm{HOC}^{*} \mathrm{C}^{*} \\
{\left[{ }^{\circ}\right]}\end{array}$ \\
\hline 0.00 & 0.37 & -146.1 & 11.7 & -169.7 & 78.3 & 69.5 & 0.00 & 1.03 & -167.5 & 24.3 & 24.3 & 75.2 & 75.2 \\
\hline 0.02 & 0.88 & -142.6 & -172.7 & -172.7 & & & 7 & 0.83 & -86.4 & 49.3 & 49.3 & 57.0 & 57.0 \\
\hline 0.13 & 0.71 & 60.7 & 177.0 & 177.0 & 65.8 & 65.8 & 0.91 & 0.96 & -82.3 & 47.6 & -128.3 & 58.8 & 51.5 \\
\hline 0.16 & 1.24 & -150.4 & 12.8 & 12.8 & 75.6 & 75.5 & 0.93 & 0.17 & -164.5 & 24.9 & -152.5 & 78.3 & 66.0 \\
\hline 0.27 & 0.73 & -112.0 & 41.7 & -139.2 & 61.9 & 58.7 & 0.97 & 0.10 & 47.0 & 26.8 & 26.7 & 58.2 & 68.2 \\
\hline 0.31 & 0.60 & -107.0 & -134.6 & -134.6 & 58.2 & 58.2 & 1.68 & 0.42 & -74.6 & -125.4 & -125.4 & 52.5 & 52.5 \\
\hline 0.42 & 1.16 & -114.7 & 41.5 & 41.5 & 61.2 & 61.2 & 1.75 & 1.15 & 54.3 & 30.4 & -154.4 & 64.6 & 60.8 \\
\hline 0.52 & 0.23 & 50.8 & 11.7 & 11.7 & 66.5 & 66.5 & 2.11 & 1.30 & -163.3 & -150.1 & -150.1 & 67.9 & 67.9 \\
\hline 0.62 & 1.18 & 57.0 & 11.0 & -173.7 & 65.8 & 64.6 & 2.17 & 0.11 & 60.6 & 5.4 & 34.5 & 68.0 & 50.0 \\
\hline 1.05 & 1.05 & -155.0 & 156.1 & -172.6 & 170.5 & 61.7 & 2.20 & 0.80 & 56.3 & -160.5 & -160.5 & 59.8 & 59.8 \\
\hline 1.34 & 1.40 & -157.5 & 156.9 & 11.5 & 170.0 & 63.6 & 2.71 & 1.13 & 63.3 & 8.2 & -156.0 & 63.8 & 47.3 \\
\hline 1.68 & 1.21 & 156.3 & -135.0 & -135.0 & 55.8 & 55.9 & 2.73 & 1.37 & 176.3 & 89.2 & 43.3 & 37.9 & -50.1 \\
\hline 2.01 & 0.36 & 150.4 & 43.5 & -133.6 & 59.3 & 56.7 & 2.80 & 1.16 & -169.3 & 178.6 & 20.9 & 176.5 & 68.1 \\
\hline 3.19 & 1.12 & 65.2 & 161.3 & 50.7 & 174.2 & 66.5 & 2.82 & 0.79 & 179.7 & 87.9 & -141.4 & 41.2 & -50.6 \\
\hline 3.31 & 1.27 & 67.6 & 159.5 & -135.9 & 175.9 & 66.6 & 2.82 & 1.26 & 170.6 & 93.0 & 93.1 & -42.0 & -42.0 \\
\hline
\end{tabular}

The lowest energy arc (in Hartree) - 0.433049 for AM1 and -0.409297 for PM3.

$\Delta E$ - relative energy of the conformer. D - dipole momentum. 
that conformational maps of both the acid and the ester are very similar, whereas they differ significantly from the amide map. In the case of the acid and the ester the preferred conformation (A on the conformational map) is the one with hydrogen bond between $\mathrm{OH}$ and $\mathrm{O}=\mathrm{C}$ groups. This corresponds to the situation where both $\mathrm{O}-\mathrm{CC}=\mathrm{O}$ and HOCC dihedrals are equal to $0^{\circ}$. The other minima (B) are symmetry related and the corresponding conformation is stabilized by hydrogen bond between $\mathrm{OH}$ as a donor and the methoxyl oxygen or carboxylic hydroxyl oxygen as an acceptor in the ester and acid molecules, respectively. In addition for both hydroxyacetic acid and its ester we observe two shallow symmetry related minima (C) with HOCC dihedral about $180^{\circ}$ and $\mathrm{O}-\mathrm{CC}=\mathrm{O}$ torsion angle about $150^{\circ}$ or $210^{\circ}$, and another shallow minimum (D) for $\mathrm{HOCC}$ about $180^{\circ}$ and $\mathrm{O}-\mathrm{CC}=\mathrm{O}$ about $0^{\circ}$

Existing theoretical data concerning hydroxyacetic acid were derived from abinitio calculations at RHF/4-31G level and from molecular mechanics calculations [11], They are generally in line with our calculations with some exceptions. In our calculations we observe two symmetry related minima (B), whereas earlier ab-initio calculations predicted only one minimum (A). On the other hand, molecular mechanics calculations, like ours, besides the (A) minimum also predicted two symmetry related minima (B), but failed to locate shallow minima (C and D). Due to low resolution of published conformational map of early ab-initio calculations for hydroxyacetic acid we are not able to say whether at 4-31G basis these shallow minima exist.

In the case of hydroxyacetamide similarly as for hydroxyacetic acid and its ester we observe deep wade minimum (A) for both $\mathrm{O}-\mathrm{CC}=\mathrm{O}$ and $\mathrm{HOCC}$ dihedrals about $0^{\circ}$. However there is another wide and deep energetic minimum $(\mathrm{Y})$ for both HOCC and $\mathrm{OCC}=\mathrm{O}$ torsion angles about $180^{\circ}$ and this conformer is stabilized by hydrogen bond between the amide hydrogen and the hydroxyl oxygen atoms.

\section{2. (R,R)-tartaric acid derivatives}

\subsection{1. ( $\mathrm{R}, \mathrm{R})$ tartaric acid $(A C)$}

Selected semiempirical results for $(\mathrm{R}, \mathrm{R})$-tartaric acid are presented in Table 1 [25], AM1 method predicts the T conformer as the lowest energy one. This conformer possesses $\mathrm{C}_{2}$ symmetry and is stabilized by hydrogen bonds between $\alpha-\mathrm{OH}$ group and carboxylic hydroxyl oxygen atoms (type $b$ see Fig. 3). The following $\mathrm{T}$ conformer differs by rotation about one of the $\mathrm{C}^{*}-\mathrm{C}$ bonds of $180^{\circ}$. It is stabilized by one hydrogen bond of the $b$ type (like the lowest energy form) and the other between $\alpha-\mathrm{OH}$ and $\mathrm{O}=\mathrm{C}$ group (the $a$ type). The next conformer is also a $\mathrm{T}$ one and again it possesses $\mathrm{C}_{2}$ symmetry because of rotation of the second carboxylic group. It is stabilized by hydrogen bonds, both of the $a$ type. The fourth conformer, $\mathrm{G}^{+}$, has also $\mathrm{C}_{2}$ symmetry with hydrogen bonds between $\beta-\mathrm{OH}$ and $\mathrm{O}=\mathrm{C}$ groups (the $d$ type).

The PM3 method prefers the T conformer with two hydrogen bonds of the $a$ type. The following conformer is the $\mathrm{G}^{-}$one and is stabilized by two hydrogen bonds of 
the $a$ type. The next conformer in energetical sequence is the $\mathrm{T}$ conformer with hydrogen bonds of the $a$ and the $b$ type.<smiles>[X]C(=O)C(C)(C)O</smiles>

a type<smiles>COC(=O)OC(C)C</smiles>

$b$ type<smiles>CC(=O)OC(C)C</smiles>

$c$ type<smiles></smiles>

Fig. 4. Types of selected hydrogen bonds. $\mathrm{X}$ is $\mathrm{O}$ for $A C$ and $M E$ or $\mathrm{N}$ for $A M$ and $T M A$.

Results of ab-initio calculations [9] showed that the $\mathrm{T}$ conformer with both hydrogen bonds of the type $a$ is of the lowest energy and only PM3 gave the same indications. While the results of theoretical calculations show the influence of intramolecular hydrogen bonding on the preference for a certain conformation, in the crystalline state the $A C$ molecule does not form any intramolecular hydrogen bond: all hydrogen bond donors are involved in intermolecular interactions. In spite of this, its conformation is very similar to the one indicated by the ab initio [9] and PM3 methods as the minimum energy form. The observed conformer is of the $\mathrm{T}$ type and consists of two planar $\alpha$-hydroxyacid residues in which the $\mathrm{C} \alpha-\mathrm{OH}$ bonds nearly eclipse the $\mathrm{C}=0$ bonds. In such conformation one might notice a nearly parallel arrangement of the $\mathrm{C}-\mathrm{O}$ (carboxylic) and $\mathrm{C} \beta-\mathrm{H}$ bonds which can lead to the electrostatic attraction between negatively charged oxygens and positively charged hydrogens attached to the chiral carbon atoms. The influence of such attractive forces on the stabilization of molecular conformation might be significant owing to the fact that there are two such bond arrangements in one $A C$ molecule. In conclusion one might state that in the isolated molecule the $\mathrm{T}$ conformer is stabilized by both intramolecular hydrogen bonds and electrostatic attractive interactions, while in the crystal the dipole/dipole interactions predominate.

\subsection{2. ( $\mathrm{R}, \mathrm{R})$ dimethyl tartrate $(M E)$}

Selected semiempirical results are collected in Table 2 [25], We can easily notice that AM1 method prefers the asymmetrical T conformer with hydrogen bonds of the $a$ and the $b$ type at the two ends of the molecule. The next lowest energy $\mathrm{T}$ conformer, possessing $\mathrm{C}_{2}$ symmetry, is stabilized by two hydrogen bonds of the $b$ type. The third conformer is the $\mathrm{G}^{+}$one with hydrogen bonds of the $d$ type.

PM3, similarly as in the case of $A C$, predicts the $\mathrm{T}$ conformer with two hydrogen bonds of the $a$ type. This conformer is only by $0.27 \mathrm{kcal} / \mathrm{mol}$ lower in energy then the $\mathrm{G}^{-}$one with hydrogen bonds also of the $a$ type.

Conformer which was predicted as the lowest energy form in AM1 calculations corresponds to the one found on the basis of X-ray analysis in crystals of $(R, R)$ dimethyl tartrate [26], However, while in the isolated molecule such conformation is 
Tab. 3. Selected semiempirical results for (R.R)-tartaric acid diamide (AM), (ten lowest energy conformers listed with some of their properties).

\begin{tabular}{|c|c|c|c|c|c|c|c|c|c|c|c|c|c|c|c|c|c|c|c|c|}
\hline \multicolumn{7}{|c|}{ MNDO } & \multicolumn{7}{|c|}{ AM1 } & \multicolumn{7}{|c|}{ PM3 } \\
\hline$\Delta \mathbf{H}$ & D & $C C^{\circ} \mathrm{C} \cdot \mathrm{C}$ & $0-C C=0$ & $0-C Q=0$ & HOC-C" & HOC.C & $\Delta \boldsymbol{H}$ & D & $C G \cdot C \cdot C$ & D-CG=0 & D-CG=0 & $\mathrm{HOC}^{\circ} \mathrm{C}^{\circ}$ & HOC.C. & $\Delta \mathbf{H}$ & D & $\mathrm{CC}^{\circ} \cdot \mathrm{C} \cdot \mathrm{C}$ & D-CG $=0$ & D-CQ-O & HOC.'. & HOC.'C \\
\hline 0.00 & 0.9 & 57.4 & -140.5 & 63.5 & 7.4 & 4.5 & 0.00 & 3.1 & 01.3 & 14.2 & 5.5 & 85.1 & 32.5 & 0.00 & 0.2 & 73.3 & 158.6 & 158.4 & 44.1 & 43.9 \\
\hline 0.58 & 0.6 & -63.8 & 62.2 & \begin{tabular}{|l|}
61.8 \\
\end{tabular} & 57.2 & 57.2 & 0.20 & 0.6 & 57.8 & 168.2 & 168.2 & 52.8 & 52.9 & 3.56 & 3.6 & 91.3 & 4.0 & 173.5 & 103.0 & -10.2 \\
\hline 0.59 & 3.5 & 75.2 & \begin{tabular}{|l|}
-143.7 \\
\end{tabular} & -143.5 & -148.2 & 48.7 & 1.51 & 2.9 & 0.0 & 12.2 & 9.5 & 8.1 & \begin{tabular}{|l||}
-7.7 \\
\end{tabular} & 3.76 & 0.3 & 3.9 & 75.2 & 173.9 & 50.1 & 9.9 \\
\hline 0.66 & 1.6 & -159.0 & 108.1 & 108.1 & -67.6 & -67.4 & 1.89 & 1.3 & 46.1 & -15.4 & -15.5 & 156.9 & 157.0 & 3.94 & 1.4 & -68.3 & 65.3 & 65.4 & 57.4 & 57.9 \\
\hline 0.80 & 2.8 & -50.7 & 27.5 & -130.6 & 3.5 & -89.2 & 2.25 & 2.5 & 7.2 & 5.9 & -6.8 & -40.5 & 130.4 & 3.94 & 2.4 & 100.2 & 26.4 & 161.2 & 94.3 & 2.2 \\
\hline 1.03 & 2.9 & -50.6 & -129.0 & -132.6 & -102.9 & -131.1 & 3.33 & 1.4 & 66.0 & 113.6 & 177.6 & 42.5 & -77.0 & 3.95 & 2.3 & -79.5 & 47.1 & 119.2 & 66.8 & +1.2 \\
\hline 1.14 & 1.0 & -61.1 & 92.2 & 56.4 & -76.4 & -165.6 & 3.58 & 2.3 & -117.9 & 139.7 & 140.1 & 59.1 & \begin{tabular}{|l||}
59.4 \\
\end{tabular} & 3.96 & 2.2 & -176.5 & -160.6 & 88.1 & -52.9 & 51.0 \\
\hline 1.32 & 2.2 & -159.9 & 106.4 & -150.4 & $\mid-73.2$ & -81.6 & 3.59 & 3.4 & -165.1 & -130.8 & 97.8 & -79.0 & 48.2 & 3.98 & 1.8 & -73.3 & 51.0 & \begin{tabular}{|l|}
97.1 \\
\end{tabular} & 64.5 & 45.3 \\
\hline 1.33 & 1.4 & -154.9 & 42.2 & -139.1 & -170.3 & -62.7 & 3.91 & 1.5 & -154.3 & 7.8 & -117.5 & 104.2 & 51.3 & 4.03 & 2.5 & -104.8 & -179.4 & 20.2 & 5.5 & 98.6 \\
\hline 1.46 & 0.9 & -56.6 & 61.2 & 88.8 & 74.3 & -66.1 & 4.10 & 2.5 & -164.3 & -85.4 & -116.5 & -179.7 & 53.5 & 4.06 & 1.6 & -66.4 & 50.1 & 82.4 & 64.9 & 46.8 \\
\hline
\end{tabular}

Lowest heats of formation are (in $\mathrm{kcal} / \mathrm{mol}$ ) -165,91 for MNDO. -188.72 for AM1 and -174.18 for PM3. $\Delta \mathrm{H}$ (in $\mathrm{kcal} / \mathrm{mol}$ ). D (in debye). 
Tab. 4. Selected semiempirical results for $N, N, N^{\prime} N^{\prime}$-tetramethyI (R,R)-tartaric acid diamide (TMA). (ten lowest energy conformers listed with some of their properties).

\begin{tabular}{|c|c|c|c|c|c|c|c|c|c|c|c|c|c|c|c|c|c|c|c|c|}
\hline \multicolumn{7}{|c|}{ MNDO } & \multicolumn{7}{|c|}{ AM1 } & \multicolumn{7}{|c|}{ PM3 } \\
\hline$\Delta \boldsymbol{H}$ & D & $C G^{\circ} C \cdot C$ & $0-C Q=0$ & D-GG $=0$ & HOC. & HOG C & $\Delta \mathbf{H}$ & D & $\mathscr{C G} \cdot \mathscr{C}^{\circ} \mathscr{C}$ & D-GG-O & D-CB $=0$ & HOC.6. & HOC. & $\Delta H$ & D & $\mathbb{C G} \cdot \mathrm{C}^{\circ} \mathrm{C}$ & $0-G G=0$ & $0-E G=0$ & HOC. ${ }^{\circ}$ & HOC.6' \\
\hline 0.00 & 3.1 & -152.0 & 82.7 & 77.8 & -65.6 & $\mid-66.2$ & 0.00 & 3.4 & -121.0 & 132.9 & 31.0 & 49.6 & 74.9 & 0.00 & 2.3 & -80.2 & 60.2 & 59.9 & 56.2 & 56.3 \\
\hline 0.20 & 3.9 & $\mid-177.5$ & 25.8 & 34.4 & -164.3 & \begin{tabular}{|l|l|}
3 & 61.8 \\
\end{tabular} & \begin{tabular}{|l|}
0.54 \\
\end{tabular} & 1.2 & 61.6 & 146.2 & 146.2 & 65.4 & 65.2 & \begin{tabular}{|l|}
1.05 \\
\end{tabular} & 5.2 & 74.4 & 33.0 & 17.5 & 71.8 & 77.2 \\
\hline 0.21 & 1.2 & -68.3 & 64.1 & 3.4 & 56.8 & 56.5 & \begin{tabular}{|l|}
0.85 \\
\end{tabular} & 2.6 & 29.5 & 21.4 & -131.7 & 87.7 & 41.7 & \begin{tabular}{|l|}
1.56 \\
\end{tabular} & 4.6 & 174.1 & 88.5 & 90.6 & -40.5 & -38.4 \\
\hline 0.42 & 3.5 & \begin{tabular}{|l|}
-165.3 \\
\end{tabular} & 53.2 & 69.6 & -93.1 & 47.8 & \begin{tabular}{|l|}
0.90 \\
\end{tabular} & 0.0 & -105.2 & 109.9 & 109.1 & 53.9 & 53.6 & \begin{tabular}{|l|}
2.11 \\
\end{tabular} & 2.5 & 52.3 & 33.6 & 33.6 & \begin{tabular}{|l|}
72.5 \\
\end{tabular} & 72.5 \\
\hline 0.57 & 3.6 & 179.1 & 40.6 & 40.9 & 9.9 & 69.9 & \begin{tabular}{|l|}
1.24 \\
\end{tabular} & 1.2 & 58.2 & 174.7 & 149.2 & 57.5 & 6.7 & .54 & 1.5 & -72.3 & 52.3 & 8.9 & 69.0 & -16.5 \\
\hline 0.61 & 1.2 & -60.5 & 87.6 & 96.0 & -82.9 & -152.4 & \begin{tabular}{|l|}
1.75 \\
\end{tabular} & 1.1 & -111.8 & 124.0 & 124.1 & 56.7 & 56.7 & \begin{tabular}{|l|}
2.60 \\
\end{tabular} & 5.1 & 179.1 & $\begin{array}{l}53.8 \\
\end{array}$ & 85.9 & -47.0 & 32.2 \\
\hline 0.75 & 2.9 & -149.8 & 72.3 & 74.1 & -78.2 & $|-62.2|$ & \begin{tabular}{|l|}
1.80 \\
\end{tabular} & 2.5 & -161.0 & 102.6 & -158.7 & 48.2 & -78.2 & 3.27 & 1.9 & 83.0 & 127.0 & 126.8 & 54.2 & 53.8 \\
\hline 0.80 & 3.7 & \begin{tabular}{|l|}
-176.8 \\
\end{tabular} & 38.6 & 50.3 & 59.3 & -154.5 & \begin{tabular}{|l|}
2.00 \\
\end{tabular} & 4.5 & -98.8 & 48.9 & 47.2 & 57.9 & 58.5 & \begin{tabular}{|l|}
3.32 \\
\end{tabular} & 1.2 & -152.3 & \begin{tabular}{|l|}
30.4 \\
\end{tabular} & -152.8 & 80.9 & 67.6 \\
\hline 0.83 & 1.9 & -172.0 & 168.9 & 30.6 & -166.0 & 67.6 & 2.11 & 0.7 & -162.1 & 104.3 & 141.9 & 39.7 & -73.0 & 3.41 & 3.8 & $|-158.7|$ & 84.1 & 84.1 & -46.9 & -47.7 \\
\hline 0.86 & 1.3 & $|-177.7|$ & 21.8 & 177.8 & -162.8 & 69.0 & \begin{tabular}{|l|}
2.15 \\
\end{tabular} & 0.4 & 15.2 & 20.2 & 20.1 & 3.8 & 94.3 & \begin{tabular}{|l|}
3.47 \\
\end{tabular} & 2.5 & -174.3 & 82.5 & -147.6 & 44.3 & -50.4 \\
\hline
\end{tabular}

Lowest heats of formation are (in kcal/mol) -151.28 for MNDO. -165.58 for AM1 and -175.38 for PM3. $\Delta \mathbf{H}$ (in kcal/mol). D (in debye). 
stabilized by intramolecular hydrogen bonds of the $a$ and $b$ type, in the crystalline state there is no indication of the presence of these types of hydrogen bonds. Instead, weak intramolecular hydrogen bond between two vicinal hydroxyl groups is observed [26], Like in the case of $A C$, the molecule consists of two planar halves which are combined together to form the staggered $T$ conformation. This gives rise to antiparallel arrangement of two pairs of $\mathrm{CO} / \mathrm{C}^{*}(\beta) \mathrm{H}$ bonds. Electrostatic attraction between the two pairs of dipoles might have a stabilizing effect on the conformation, despite the presence or absence of intramolecular hydrogen bonds.

\subsection{3. (R, R)-tartaric acid diamide $(A M)$}

Selected results of semiempirical calculations are collected in Table 3 [25], MNDO predicts the $\mathrm{T}$ conformer as the most stable one. The following is the $\mathrm{G}^{-}$form with energy difference of $0.58 \mathrm{kcal} / \mathrm{mol}$. AM1 points at eclipsed conformer as the lowest energy form. This conformer is stabilized by bifurcated hydrogen bonds. This is a well known tendency of AM1 to optimize staggered geometries to eclipsed ones with bifurcated hydrogen bonds [12,18], The following conformer is the $\mathrm{G}^{+}$form with relative energy $0.2 \mathrm{kcal} / \mathrm{mol}$. It is stabilized by hydrogen bonds of two types $c$ and $d$ as defined in Fig. 4.

According to PM3 the $\mathrm{G}^{+}$conformer with hydrogen bonds of $d$ type is preferred and the following conformer is the $\mathrm{G}^{-}$form with energy difference of 3.56 $\mathrm{kcal} / \mathrm{mol}$.

\subsection{4. $\mathrm{N}, \mathrm{N}, \mathrm{N}^{\prime}, \mathrm{N}^{\prime}$-tetramethyl $(\mathrm{R}, \mathrm{R})$-tartaric acid diamide $(T M A)$}

Table 4 presents selected semiempierical results for TMA [25], MNDO method prefers two $\mathrm{T}$ conformations. The $\mathrm{G}^{-}$form is the third in energetical sequence with relative energy of $0.21 \mathrm{kcal} / \mathrm{mol}$.

AM1 again favours an eclipsed conformer, like for $A M$, but the $\mathrm{G}^{+}$ conformation with hydrogen bonds of the $d$ type is just following with energy difference of $0.54 \mathrm{kcal} / \mathrm{mol}$.

PM3 predicts the $\mathrm{G}^{-}$conformer to be of the lowest energy. Similar conformer was found to be present in crystal structure of TMA. The second conformer with relative energy of $1.05 \mathrm{kcal} / \mathrm{mol}$ has the $\mathrm{T}$ form with hydrogen bonds of the $a$ type.

\section{Conclusions}

Semiempirical methods MNDO, AM1 and PM3 are valuable in examination of conformers, their stable geometries and energy differences. Because of the demands made on computer resources these methods should be used prior to ab-initio computations even for medium size molecules. Semiempirical methods allow to reduce the number of possible conformers before further studies. Moreover, AM1 and PM3 methods are especially valuable for predicting stable geometries of molecules with intramolecular hydrogen bonds. It seems that in cases when AM1 and PM3 point at the 
same conformer as the preferred one, (not counting an eclipsed conformer commonly indicated by AM1), the same results will come out from ab-initio calculations.

Our calculations have also shown that $(\mathrm{R}, \mathrm{R})$-tartaric acid and its ester derivatives tend to adopt extended conformation with carboxyl groups trans to each other. It is in a very good agreement with experimental data derived from X-ray diffraction [3,26], VCD [9], ROA [15,16], and ${ }^{13} \mathrm{C}$ NMR methods [13,14],

In the case of both examined diamides semiempirical methods gave non consistent results. However for $\mathrm{N}, \mathrm{N}, \mathrm{N}^{\prime}, \mathrm{N}^{\prime}$-tetramethyl diamide of $(\mathrm{R}, \mathrm{R})$-tartaric acid the PM3 method predicted conformer similar to that obtained from the crystal structure analysis [26].

\section{Acknowledgment}

The authors are grateful to Poznan Super Computing and Networking Center for a grant of computer time on CRAY J916. This work was partially supported by KBN grant No T11FO10 08p01.

\section{References:}

[1] Pasteur L., Ann. Chim. Phys., 24, 442, (1848).

[2] Bijvoet J. M.; Peerdman A. F.; Bommel A. J. van, Nature, 168, 271, (1951).

[3] Okaya Y.; Stemple N. R.; Kay M. I, Acta Cryst., 21, 237, (1966).

[4] Gawronski J.; Gawronska K.; Rychlewska U., Tetrahedron Lett., 30, 6071, (1989).

[5] Rychlewska U., Acta Cryst., C48, 965, (1992).

[6] Marcott C.; Blackburn C. C.; Faulkner T. R.; Moscowitz A.; Overend J., J. Am. Chem. Soc., 100, 5262, (1978).

[7] Su C. N.; Keiderling T. A., J. Am. Chem. Soc., 102, 511, (1980).

[8] Freedman T. B.; Balukjian G. A.; Nafie L. A., J. Am. Chem. Soc., 107, 6213, (1985).

[9] Polvarapu P. L.; Ewig C. S.; Chandramouly T., J. Am. Chem. Soc., 109, 6213, (1985).

[10] For references for the various split-valence basis sets, explanations of basis set notation, and the RHF method see: Hehre, W. J.; Radom L.; Schleyer P. v. R.; Pople J. A., Ab Initio Molecular Orbital Theory, Wiley; New York, 1986.

[11] Stouten P. F. W.; Kroon-Batenburg L. M. J.; Kroon J., J. Mol. Structure (Theochem), 200, 169, (1989).

[12] Szarecka A.; Hoffmann M.; Rychlewski J., Rychlewska U.; J. Mol. Structure, 374, 362, (1996).

[13] Ascenso J.; Gil V. M. S., Can. J. Chem., 58, 1376, (1980).

[14] Hasan M., Org. Magn. Res., 14, 309, (1980).

[15] Barron L. D., Tetrahedron, 34, 607, (1978).

[16] Barron L. D.; Gargano A. R.; Hecht L.; Polvarapu P. L.; Sugeta H., Spectrochim. Acta, 48A, 1051,(1992). 
[17] Rademacher P.; Strukturen Organischer Verbindungen, VCH, Weinheim, 1987.

[18] Cramer C. J.; Truhlar D. G., J. Am. Chem. Soc., 99, 3892, (1994).

[19] Pople J. A.; Beveridge D. L., Approximate Molecular Orbital Theory, McGrawHill; New York, 1970.

[20] Dewar M. J. S.; Thiel W., J. Am. Chem. Soc., 99, 4899, (1977).

[21] Dewar M. J. S.; Zoebisch E. G.; Healy E. F.; Stewart J. J. P, J. Am. Chem. Soc., 107, 3902, 1985.

[22] Stewart J. J. P., J. Comp. Chem., 10, 209, (1989).

[23] Gaussian 94, Revision C.3, Frisch M. J.; Trucks G. W.; Schlegel H. B.; Gill P. M. W.; Johnson B. G.; Robb M. A.; Cheeseman J. R; Keith T.; Petersson G. A.; Montgomery J. A.; Raghavachari K.; Al-Laham M. A.; Zakrzewski V. G.; Ortiz J. V.; Foresman J. B.; Cioslowski J.; Stefanov B. B.; Nanayakkara A.; Challacombe M.; Peng C. Y.; Ayala P. Y.; Chen W.; Wong M. W.; Andres J. L.; Replogle E. S.; Gomperts R.; Martin R. L.; Fox D. J.; Binkley J. S.; Defrees D. J.; Baker J.; Stewart J. P.; Head-Gordon M.; Gonzalez C.; Pople J. A., Gaussian Inc., Pittsburgh PA, 1995. [24] J. J. P. Stewart, MOPAC manual 6th edn., Frank J. Seiler Research Laboratory, US Air Force Academy, CO 80840, 1990.

[25] Tables of all 270 conformers examined in semiempirical calculations can be obtained on request from the authors.

[26] Rychlewska U. unpublished data. 